Received 00th January 20xx, Accepted 00th January 20xx DOI: $10.1039 / x 0 x \times 00000 x$

\title{
Selective dihydroxylation of methyl oleate to methyl-9,10- dihydroxysterate in the presence of a recyclable tungsten based catalyst and hydrogen peroxide
}

\author{
Nahla Araji, ${ }^{a}$ Gregory Chatel, ${ }^{* b}$ Audrey Moores, ${ }^{* c}$ François Jérôme ${ }^{a}$ and Karine De Oliveira Vigier*a
}

\begin{abstract}
The dihydroxylation of fatty methyl esters is of prime importance for the synthesis of surfactants and lubricants. The conversion of methyl oleate (MO) to $98 \%$ yield of methyl-9,10-dihydroxysterate (MDHS) was performed in the presence of $\mathrm{H}_{2} \mathrm{O}_{2}$ and $\mathrm{H}_{3} \mathrm{PW}_{12} \mathrm{O}_{40}$ catalyst in absence of a phase transfer agent. The study of the effect of hydrogen peroxide concentration revealed that significant catalytic activity was only achieved for an optimal amount of $\mathrm{H}_{2} \mathrm{O}_{2}$. A mechanism for this reaction was proposed where hydrogen peroxide reacts with $\mathrm{H}_{3} \mathrm{PW}_{12} \mathrm{O}_{40}$ to produce peroxo-phosphotungstate anions, which directly dihydroxylate MO. The recyclability of the catalyst was also studied. To this aim, a recyclable form of the heteropolyacid was synthesized using $\mathrm{Cs}$ cations $\left(\mathrm{Cs}_{2.3} \mathrm{H}_{0.7} \mathrm{PW}_{12} \mathrm{O}_{40}\right)$. This catalyst was recycled up to three cycles without significant loss in catalytic performances.
\end{abstract}

\section{Introduction}

Fatty acid methyl esters (FAME) received a lot of attention as a source of value-added chemicals owing to their low price and the fact that they can be converted into several multifunctionalized molecules through a relatively small number of synthetic transformations. Thus, FAME is an important starting material in a number of reported reactions, in particular, the production of biodiesel through esterification reactions, ${ }^{1-8}$ and the oxidative functionalization of FAMEs to produce epoxides or acids used in a broad range of industrial applications such as lubricants, plasticizers, hydraulic fluids, pharmaceuticals for skin diseases and cosmetic auxiliaries. ${ }^{7,9}$ Presently, many reactions can be performed from $\mathrm{C}=\mathrm{C}$ transformation of this class of molecules, but the most investigated are epoxidation and $\mathrm{C}-\mathrm{C}$ cleavage reactions. ${ }^{10-12}$ One interesting reaction is the dihydroxylation of FAME or fatty acids to produce the corresponding diols which are used for the manufacture of surfactants and lubricants. This reaction can be performed through two mechanism pathways (Scheme 1).

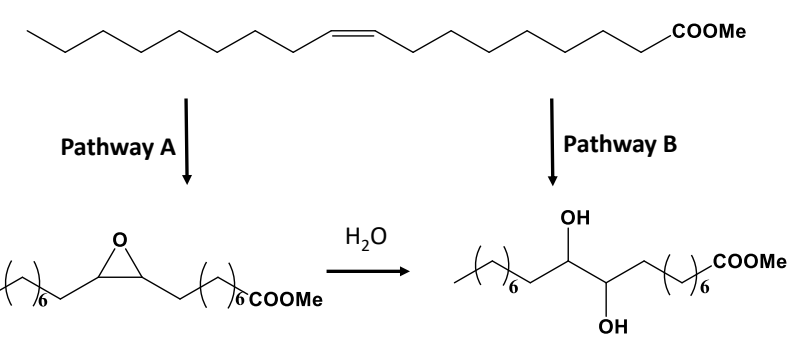

Scheme 1. Reaction pathways for the dihydroxylation of methyl oleate.

\footnotetext{
a. IC2MP, UMR CNRS 7285-Université de Poitiers, France, ENSIP, B1, 1 rue Marcel Doré, TSA 41105, 86073 Poitiers Cedex 9, France.

b. Univ. Savoie Mont Blanc, LCME, F-73000 Chambéry, France.

c. Centre for Green Chemistry and Catalysis, Department of Chemistry, McGill

University, 801 Sherbrooke St. West, Montreal, H3AOB8, Quebec, Canada.
}

The first pathway (A) is the formation of diols via epoxidation of the double bond and hydrolytic cleavage by water. In this pathway, it is of importance to mention that this reaction sequence was often used without detection or isolation of the intermediately formed epoxides. Catalysts used for this reaction are essentially based on W or Mo. ${ }^{13-18}$ One can mention that in many studied reactions, diols are often observed as intermediates in the full cleavage reaction, and are considered as intermediates or by-products resulting from the epoxidation of the double bond, but they are not the targeted products. ${ }^{11}$ The second pathway $(B)$ is the direct dihydroxylation of the double bond. The direct dihydroxylation reaction (pathway $B$ ) of unsaturated fatty acids or esters was reported with Os or Ru based catalysts and various co-oxidants to reoxidize the reduced metal species, e.g. hydrogen peroxide, tert-butyl hydroperoxide, $\mathrm{N}$-methylmorpholin- $\mathrm{N}$-oxide or potassium hexacyanoferrate (III). ${ }^{19}$ The direct dihydroxylation was also performed using stoichiometric amount of permanganate. New Os-containing catalysts were also investigated in the presence of molecular oxygen ${ }^{20}$ leading to diols used for the manufacture of surfactants. For example, $85 \%$ of methyl-9,10dihydroxysterate (MDHS) were obtained from methyl oleate (MO) using a mixture of THF and water, with a THF/ $\mathrm{H}_{2} \mathrm{O}$ volume ratio of $3: 1$ as solvent, in the presence of $\mathrm{OsO}_{4}$ and 4methylmorphine $\mathrm{N}$-oxide. ${ }^{21} \mathrm{MDHS}$ was used in that work as an intermediate for the synthesis of lubricity improver which contains at least one 1,2-dimethoxyester. All methods mentioned above to produce diols present several drawbacks, including the use of organic solvents without recovery, the reliance on more than one step to produce the desired product and sometimes the need for expensive and toxic oxidants. Among the usual oxidants used, $\mathrm{H}_{2} \mathrm{O}_{2}$ is considered as an attractive candidate since it is produced annually in $2.2 \times 10^{6}$ tons worldwide, almost exclusively ( $>95 \%$ ) by means of the 
alkylanthraquinone autoxidation process, and only leads to water molecules as by-products when it is used in an oxidation reaction. ${ }^{22}$ The $\mathrm{H}_{2} \mathrm{O}_{2}$-mediated direct dihydroxylation of unsaturated fatty acids or esters was studied in the presence of a Fe-tetra amido macrocylic complex ${ }^{23}$ or a resin-supported sulfonic acid under metal-free conditions without any organic solvent. ${ }^{24}$ In this study, they used Nafion SAC- 13 at $90^{\circ} \mathrm{C}$ in the presence of $30 \%$ of $\mathrm{H}_{2} \mathrm{O}$ at $70^{\circ} \mathrm{C}$ for $20 \mathrm{~h}$ affording $80 \%$ yield of the diols from oleic acid. Piazza et al. showed that aluminacatalyzed hydrolysis of fatty epoxides is an efficient way to synthesize polyhydroxy materials. ${ }^{25}$ Cecchini et al. reported the oxidation of FAMEs (methyl oleate, methyl linoleate and methyl linolenate) using oxovanadium complexes in the presence of $\mathrm{CHCl}_{3}$ as solvent, where the best yield in $\mathrm{MDHS}$ was $87 \%$ along with $13 \%$ of epoxide after $6 \mathrm{~h}$ reaction at $50{ }^{\circ} \mathrm{C} .{ }^{26} \mathrm{H}_{2} \mathrm{O}_{2}$ is widely used as oxidant in biomass conversion to chemicals and some examples reported the combination of $\mathrm{H}_{2} \mathrm{O}_{2}$ and tungstic acid for fatty acids conversion to dicaboxylic acids, azelaic acid, etc. ${ }^{27}$ For example, a high conversion of $90 \%$ and $80 \%$ selectivity in desired diol during dihydroxylation reaction was observed in the presence of this system. One can mention that a concentrated solution of $\mathrm{H}_{2} \mathrm{O}_{2}(>60 \%)$ is required and should be added continuously to convert fatty acids. ${ }^{28,29}$ The use of an excess of $\mathrm{H}_{2} \mathrm{O}_{2}$ is problematic on large scales due to safety considerations. ${ }^{30}$ In the case of low concentrated solution of $\mathrm{H}_{2} \mathrm{O}_{2}$, the sheer volume of the aqueous reagents required can be detrimental to the reaction and phase transfer agent are required.

The synthesis of diols from FAME require the control the selectivity and a concentrated solution of $\mathrm{H}_{2} \mathrm{O}_{2}$. In order to use a low concentrated solution of $\mathrm{H}_{2} \mathrm{O}_{2}$, mass transfer agent are often used in order to reach a yield to diols over $70 \%$. The catalysts used for this reaction are often homogeneous ones and not recyclable. Herein, we wish to demonstrate that methyl-9,10-dihydroxystearate (MDHS) can be produced from methyl oleate (MO) using a one step process without the addition of an organic solvent or a mass transfer agent in the presence of an aqueous solution of $\mathrm{H}_{2} \mathrm{O}_{2}$ (30\%). Peroxophosphotungstate (POW) based catalyst can be used to perform epoxidation reaction in a biphasic media containing an organic solvent as demonstrated by the work of Venturello and D'Aloisio. ${ }^{31,32}$ Previously, we have shown that an amphiphilic dipyridinium peroxo-phoshotungstate ion pair was selective and recyclable catalyst for the triphasic epoxidation of fatty acids and esters with hydrogen peroxide. ${ }^{33}$ Based on these results and on the state of the art, tungsten based catalyst $\left(\mathrm{H}_{3} \mathrm{PW}_{12} \mathrm{O}_{40}\right)$ were chosen to synthesize MDHS. This catalysts was studied without the use of a phase transfer agent or organic solvent. We also developed a recyclable version of this catalyst (and $\mathrm{Cs}_{2.3} \mathrm{H}_{0,7} \mathrm{PW}_{12} \mathrm{O}_{40}$ ) relying on a cation exchange with $\mathrm{Cs}^{2+}$.

\section{Experimental}

Materials and methods
Hydrogen peroxide ( 30 wt\% aqueous $\mathrm{H}_{2} \mathrm{O}_{2}$ ) purchased from Acros-Organics was used as primary oxidant. Methyl Oleate (MO), from Alfa Aesar, was purchased with a purity of $96 \%$ and phosphotungstic acid $\mathrm{H}_{3} \mathrm{PW}_{12} \mathrm{O}_{40}$, from Sigma-Aldrich, was used as an acid catalyst. 9,10-Epoxy methyl stearate (epoxide) was purchased with $99 \%$ purity from Santa Cruz factory from Toronto and was used as a calibration standard to quantify the yield of the produced epoxide. In order to quantify MDHS (methyl-9,10-dihydroxystearate) was synthesized with a a $80 \%$ purity from the oxidation of methyl oleate for quantification purposes. The purity of MDHS was verified by NMR and LCMS analysis and the MDHS was then used as a calibration standard. The carbon mass balance was checked by ${ }^{1} \mathrm{H}$ NMR and masss spectrometry analysis.

\section{Catalytic tests}

All catalytic experiments were carried out in a $50 \mathrm{~mL}$ glass flask fitted with reflux, starting from $5 \mathrm{mmol}$ of the substrate (methyl oleate) in the presence of $5 \mathrm{wt} \%$ of catalyst and the desired amount of aqueous $\mathrm{H}_{2} \mathrm{O}_{2}$ (30\%) (from 1.1 eq. (0.63g) to 1.5 eq. $(0.86 \mathrm{~g}))$. The reaction mixture was stirred $(1400 \mathrm{rpm})$ at the defined temperature (from 50 to $80^{\circ} \mathrm{C}$ ). At the end of the reaction, the reaction media was cooled down rapidly and the organic phase was extracted using ethyl acetate $(40 \mathrm{~mL})$ and dried over anhydrous $\mathrm{Na}_{2} \mathrm{SO}_{4}$. After evaporation of the solvent, the sample was diluted using $1 \mathrm{~mL}$ of pyridine and silylated by adding hexamethyldisilazane $(1 \mathrm{~mL})$ and chlorotrimethylsylane (1 $\mathrm{mL}$ ). Sorbitol ( $2 \mathrm{mg}$ ), used as external standard, was added to the sample before analysis by GC-FID. Each result corresponds to one experiment, and no sample was taken.

\section{GC-FID analyses}

Gas chromatography analyses (GC-FID) were performed using an Agilent Technologies 456 series instrument equipped with a flame ionization detector, using a column of $30 \mathrm{~m} \times 0.25 \mathrm{~mm} \times 0.5$ $\mu \mathrm{m}$ film thickness composed with phenyl (5\%) dimethyl siloxane (95\%).

The conversion values of methyl oleate was calculated as shown below:

$$
\text { Conversion }(\%)=\frac{A_{M O}^{i} / A_{\text {sorbitol }}-A_{M O}^{t} / A_{\text {sorbitol }}}{A_{M O}^{i} / A_{\text {sorbitol }}} \times 100
$$

Where $\boldsymbol{A}_{M \boldsymbol{O}}^{\boldsymbol{i}}$ and $\boldsymbol{A}_{M \boldsymbol{M}}^{\boldsymbol{t}}$ represent the values of the area of methyl oleate chromatographic peaks respectively at the initial time (time zero) and time of control. $\boldsymbol{A}_{\text {sorbitol }}$ is the area of the external standard.

The yields of products (MDHS and epoxide) at time of control t were calculated as shown below:

$$
\text { Yield }(\%)=\frac{\text { mol of product formed }}{\text { initial mol of methyl oletate }} \times 100
$$

Where $\boldsymbol{A}_{\boldsymbol{p}}^{\boldsymbol{i}}$ and $\boldsymbol{A}_{\boldsymbol{p}}^{\boldsymbol{t}}$ represent the values of the area of the product (MDHS or epoxide) chromatographic peaks respectively at the initial time (time zero) and time of control. The margin error for yields and conversions is around $3 \%$ for all the results. 


\section{Results and discussion}

In a first set of experiments, $5 \mathrm{wt} \%$ of phosphotungstic acid $\left(\mathrm{H}_{3} \mathrm{PW}_{12} \mathrm{O}_{40}\right)$ was added to $5 \mathrm{mmol}$ of methyl oleate (MO) in the presence of 1.1 eq. of $\mathrm{H}_{2} \mathrm{O}_{2}$ at $80{ }^{\circ} \mathrm{C}$ (Figure 1). After 2 min of reaction, $15 \%$ of $\mathrm{MO}$ was converted and MDHS was produced with $14 \%$ yield. Upon prolonged reaction time, conversion of MO reached a maximum of $85 \%$ after $2 \mathrm{~h}$ of reaction with yields of $84 \%$ and $1 \%$ in MDHS and epoxide, respectively. Interestingly, $\mathrm{H}_{3} \mathrm{PW}_{12} \mathrm{O}_{40}$ in the presence of $\mathrm{H}_{2} \mathrm{O}_{2}$ featured an impressive selectivity to $\mathrm{MDHS}$ of over $99 \%$ throughout the reaction duration.

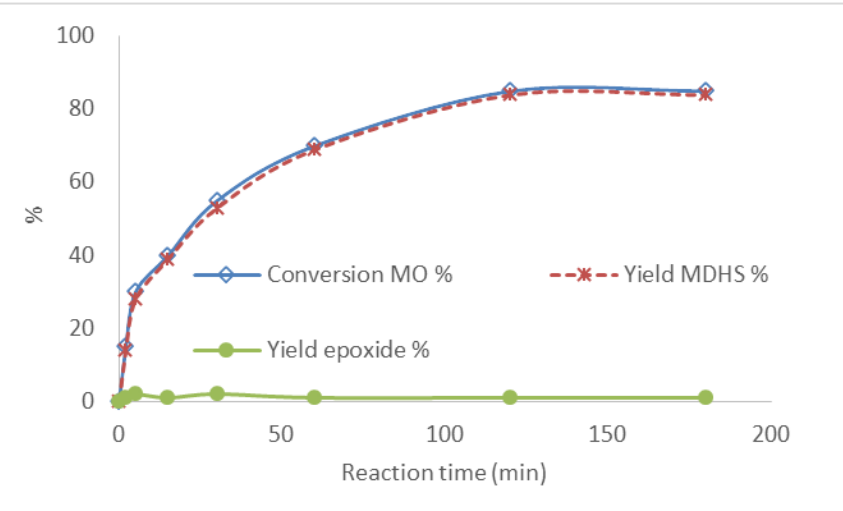

Figure 1. Oxidation of methyl oleate $(5 \mathrm{mmol})$ to $\mathrm{MDHS}$ and epoxide in the presence of 5 wt\% of $\mathrm{H}_{3} \mathrm{PW}_{12} \mathrm{O}_{40}$ and 1.1 eq. of $\mathrm{H}_{2} \mathrm{O}_{2}$ at $80^{\circ} \mathrm{C}$

Reaction conditions were then explored with the aim to decrease the amount of both catalyst and $\mathrm{H}_{2} \mathrm{O}_{2}$ used in the oxidation of $\mathrm{MO}$. In all experiments described hereafter, the selectivity to MDHS remained higher than $98 \%$, and thus, for simplicity, results were solely expressed in terms of $\mathrm{MO}$ conversions.

First, the acid catalyst loading was studied at $80{ }^{\circ} \mathrm{C}$ in the presence of 1.1 eq. of $\mathrm{H}_{2} \mathrm{O}_{2}$ (Figure 2).

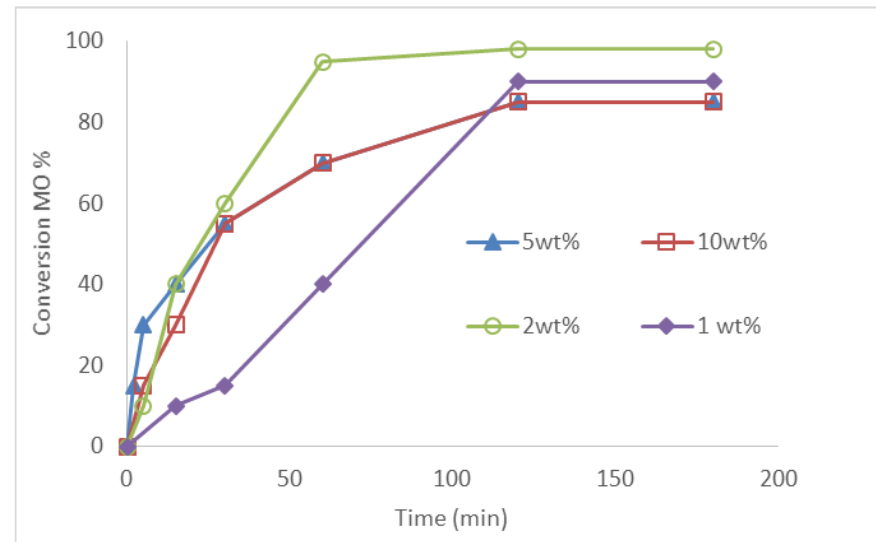

Figure 2. Effect of catalyst amount on the conversion of methyl oleate using 1.1 eq. of $\mathrm{H}_{2} \mathrm{O}_{2}, 5 \mathrm{mmol}$ of $\mathrm{MO}$ at $80^{\circ} \mathrm{C}$ (the yield in epoxide in all these experiments was less than 2\%).
The decrease in catalyst amount from $10 \mathrm{wt} \%$ to $5 \mathrm{wt} \%$ led to a slight change at the beginning of the reaction (up to $30 \mathrm{~min}$ ) and after 30 min of reaction, similar trend was observed and both catalyst loadings enabled $85 \%$ conversions after $2 \mathrm{~h}$ of reaction (Figure 2). The initial rate of the reaction increased from $165 \mathrm{~h}$ 1 to $842 \mathrm{~h}^{-1}$ from 10 to $5 \mathrm{wt} \%$ loadings. A further decrease of the amount of $\mathrm{H}_{3} \mathrm{PW}_{12} \mathrm{O}_{40}$ from 5 wt\% to $2 \mathrm{wt} \%$, led to a smaller initial reaction rate from $842 \mathrm{~h}^{-1}$ to $672 \mathrm{~h}^{-1}$ but a complete conversion of $\mathrm{MO}$ was observed after $2 \mathrm{~h}$ of reaction with a catalyst amount of $2 \mathrm{wt} \%$. For $1 \mathrm{wt} \%$ of catalyst loading, the reaction slowed significantly, with conversions systematically lower at all-time points than all of the 3 other studied loadings for a reaction time lower than $100 \mathrm{~min}$. Above $100 \mathrm{~h}$ the MO conversion is $90 \%$ against $85 \%$ for $5 \mathrm{wt} \%$ and $10 \mathrm{wt} \%$. The initial rate of the reaction was thus very low $\left(95 \mathrm{~h}^{-1}\right)$ in the presence of $1 \mathrm{wt} \%$ of catalyst and the conversion reached $90 \%$ after $2 \mathrm{~h}$ of reaction. These results suggest that an optimal loading was obtained at $2 \mathrm{wt} \%$, which can be rationalized by the fact that an excess of catalyst may lead an excessively fast decomposition of $\mathrm{H}_{2} \mathrm{O}_{2}$, while too low loadings fail to sustain the reaction as it is reported in the literature. ${ }^{34}$ At this loading, we observed the highest $\mathrm{MO}$ conversion (100\%) as well as the highest yield in MDHS (99\%), at $80{ }^{\circ} \mathrm{C}$ using 1.1 eq. of $\mathrm{H}_{2} \mathrm{O}_{2}$. It seems that it is necessary to control the ratio catalyst $/ \mathrm{H}_{2} \mathrm{O}_{2}$ to obtain good $\mathrm{MDHS}$ yields from $\mathrm{MO}$. In order to confirm this observation, the effect of $\mathrm{H}_{2} \mathrm{O}_{2}$ content on the conversion of $\mathrm{MO}$ was then studied (Figure 3). Variations in the amounts of $\mathrm{H}_{2} \mathrm{O}_{2}$ had drastic effects on the conversion. When decreased from 1.1 eq. to 0.5 eq. (molar), the conversion of $\mathrm{MO}$ decreased from $98 \%$ to $45 \%$, while the selectivity in MDHS remained high at $99 \%$ after $90 \mathrm{~min}$ of reaction. Increasing oxidant content to 1.5 eq. led surprisingly to only $1 \%$ conversion of $\mathrm{MO}$. The $\mathrm{H}_{2} \mathrm{O}_{2}$ quantity was varied by altering the volume of its $30 \mathrm{wt} \%$ aqueous solution, thus increased $\mathrm{H}_{2} \mathrm{O}_{2}$ content resulted in larger volumes of the aqueous phase. The existence of an optimum $\mathrm{H}_{2} \mathrm{O}_{2}$ content at 1.1 eq. may be explained by the fact that at lower amounts, the conversion is limited by the actual quantity of reagents available.

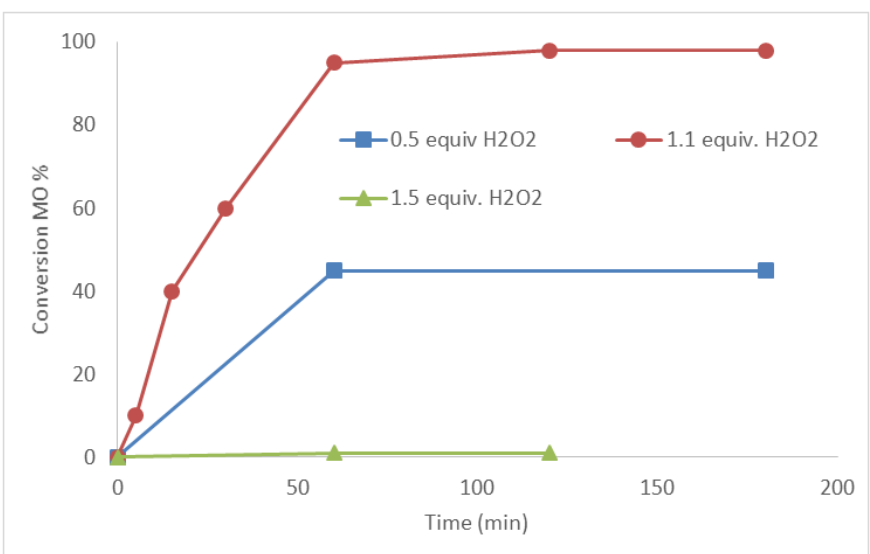

Figure 3. Effect of the hydrogen peroxide content on the conversion of methyl oleate using $5 \mathrm{mmol}$ of $\mathrm{MO}$ and $2 \mathrm{wt} \%$ of $\mathrm{H}_{3} \mathrm{PW}_{12} \mathrm{O}_{40}$ at $80{ }^{\circ} \mathrm{C}$ (the yield of epoxide in all these experiments was less than $2 \%$ ). 
If $\mathrm{H}_{2} \mathrm{O}_{2}$ was added dropwise (1.1 eq.) with a flow of $0.05 \mathrm{~mL}$.min 1 and that the reaction took place for $1 \mathrm{~h}$ after the addition of $\mathrm{H}_{2} \mathrm{O}_{2}, 78 \%$ of $\mathrm{MO}$ was converted to $77 \%$ of MDHS. If the addition flow of $\mathrm{H}_{2} \mathrm{O}_{2}$ was increased from $0.05 \mathrm{~mL}$. $\mathrm{min}^{-1}$ to $0.07 \mathrm{~mL}$. $\mathrm{min}^{-}$ 1 and the reaction was pursued for $1 \mathrm{~h}$ the conversion of $\mathrm{MO}$ reached $96 \%$ and $95 \%$ of MDHS was produced. These results showed that in this case by playing on the addition rate of $\mathrm{H}_{2} \mathrm{O}_{2}$ similar results are obtained than when $\mathrm{H}_{2} \mathrm{O}_{2}$ is added at the beginning of the reaction. At higher content ( 1.5 eq. of $\mathrm{H}_{2} \mathrm{O}_{2}$ ), the reaction may be drastically affected by the presence of a large aqueous phase when $\mathrm{H}_{2} \mathrm{O}_{2}$ was added in one time. To confirm this hypothesis, $\mathrm{H}_{2} \mathrm{O}_{2}$ (1.5 eq.) was added dropwise and we were pleased to see that with a flow rate of $0.07 \mathrm{~mL} . \mathrm{min}^{-1}$, $95 \%$ of $\mathrm{MO}$ was converted to $94 \%$ of $\mathrm{MDHS}$, after $1 \mathrm{~h}$ of reaction (after the addition of $\mathrm{H}_{2} \mathrm{O}_{2}$ ) showing that if the amount of $\mathrm{H}_{2} \mathrm{O}_{2}$ is controlled, excellent yield of MDHS can be achieved.

Based on these results, we determine that an optimal molar ratio between hydrogen peroxide and the catalyst is required (around 550) to carry out this reaction in good yield with the addition of $\mathrm{H}_{2} \mathrm{O}_{2}$ in one time. It is known that Keggin-type $\left[\mathrm{PW}_{12} \mathrm{O}_{40}\right]^{3-}$ can be transformed to peroxo-active species, $\left\{\mathrm{PO}_{4}\left[\mathrm{~W}(\mathrm{O})\left(\mathrm{O}_{2}\right)_{2}\right]_{4}\right\}^{3-}$ by an excess of hydrogen peroxide. It is a reversible redox reaction where phosphotungstic acid is generated after the oxidation of the desired substrate by peroxo-phosphotungstate anions (active form). Based on the literature a proposed catalytic mechanism for this reaction is shown in Scheme 2.

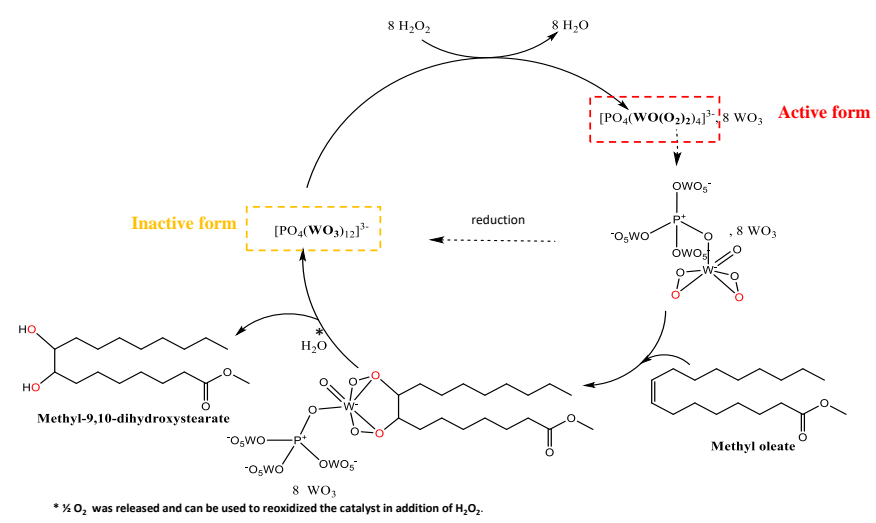

Scheme 2. Proposed mechanism of the oxidative reaction of methyl oleate in the presence phosphotungstic acid and hydrogen peroxide based on the literature.

According to the work of Noyori et al. and Strassner hydrogen peroxide is used to produce the peroxo-phosphotungstate anions that will react with $\mathrm{MO}$ in order to form a compound with tungsten that will lead to the formation of MDHS and the release of $\left[\mathrm{PO}_{4}\left(\mathrm{WO}_{3}\right)_{12}\right]^{3-}$ that can be converted again to peroxophosphotungstate anions. ${ }^{35,36}$ In order to prove that the epoxide was not an intermediate in this reaction, a complementary experiment was performed starting from epoxide instead of $\mathrm{MO}$ using $2.5 \mathrm{mmol}$ of epoxide corresponding to a $55 \%$ conversion of $\mathrm{MO}$ after $30 \mathrm{~min}$ of reaction keeping similar amount of $\mathrm{H}_{2} \mathrm{O}_{2}$ and catalyst used in the conversion of $\mathrm{MO}$ ( $0.66 \mathrm{~g}$ of $\mathrm{H}_{2} \mathrm{O}_{2}$ and $0.075 \mathrm{~g}$ of catalyst). After $30 \mathrm{~min}, 60 \%$ of the epoxide was converted to various non identified products with only $20 \%$ yield of MDHS formed. These poor yields clearly established that the epoxide can not be a significant intermediate in the dihydroxylation of OM studied herein. In the presence of $\mathrm{H}_{3} \mathrm{PW}_{12} \mathrm{O}_{40}$, the hydrolytic cleavage of epoxide was not the main route, and the mechanism of the reaction goes through a direct dihydroxylation of $\mathrm{MO}$ as described in the literature in the presence of tungstic acid. ${ }^{37}$ The effect of the reaction temperature was then studied (Figure 4). When it was decreased from $80^{\circ} \mathrm{C}$ to $60^{\circ} \mathrm{C}$, it logically took a longer time, namely $4 \mathrm{~h}$ instead of $2 \mathrm{~h}$, to reach a similar conversion of $\mathrm{MO}(98 \%$ vs. $95 \%)$. A further decrease in the temperature to $40{ }^{\circ} \mathrm{C}$ afforded poor MO conversions, the maximum observed being $20 \%$ ( $98 \%$ selectivity to $\mathrm{MDHS}$ ) after $4 \mathrm{~h}$ of reaction.

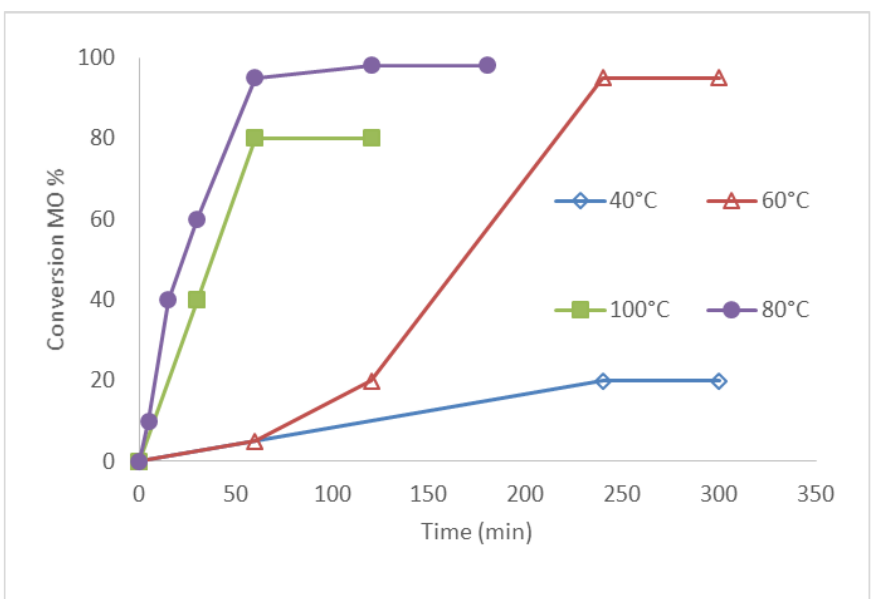

Figure 4. Effect of the temperature on the conversion of methyl oleate using 1.1 eq. of $\mathrm{H}_{2} \mathrm{O}_{2}, 5 \mathrm{mmol}$ of $\mathrm{MO}$ and $2 \mathrm{wt} \%$ of $\mathrm{H}_{3} \mathrm{PW}_{12} \mathrm{O}_{40}$ (the yield of epoxide in all these experiments was less than $2 \%$ ).

Interestingly, the increase of the reaction temperature to 100 ${ }^{\circ} \mathrm{C}$ led to a decrease in the conversion of MO from $98 \%$ to $80 \%$ after $2 \mathrm{~h}$ of reaction. In fact, hydrogen peroxide is known to not be stable at this temperature and may be degraded, which may explain the decrease in MO conversion, by limiting the formation of the active species. ${ }^{34}$ It can be pointed out that at $80^{\circ} \mathrm{C}$, a MO conversion higher than $95 \%$ was achieved after the shortest of the explored reaction times ( 1 h) with $99 \%$ selectivity of MDHS.

With the optimized reaction conditions at 1.1 eq. of $\mathrm{H}_{2} \mathrm{O}_{2}, 2$ wt\% of $\mathrm{H}_{3} \mathrm{PW}_{12} \mathrm{O}_{40}$ and $80{ }^{\circ} \mathrm{C}$, we wanted to explore catalyst recyclability. Unfortunately, phosphotungstic acid $\mathrm{H}_{3} \mathrm{PW}_{12} \mathrm{O}_{40}$ is a strong acid soluble under aqueous conditions, which leads to low $\mathrm{pH}$ around 1 under our conditions. After the reaction, it was thus impossible to simply recover an active form of the catalyst from the reaction medium. We thus explored the modification of this catalyst in order to obtain a heterogeneous catalyst. In the literature, Gharib et al. worked on the recycling of phosphotungstic acid by the substitution of hydrogen atoms by cesium $\left(\mathrm{Cs}_{2.5} \mathrm{H}_{0.5} \mathrm{PW}_{12} \mathrm{O}_{40}\right)$, using ultrasonic irradiation. ${ }^{38}$ Inspired by this study, we synthesized $\mathrm{Cs}_{2.3} \mathrm{H}_{0,7} \mathrm{PW}_{12} \mathrm{O}_{40}$, which structure was confirmed by ICP analysis. The recycling of $\mathrm{Cs}_{2.3} \mathrm{H}_{0.7} \mathrm{PW}_{12} \mathrm{O}_{40}$ was then performed using the optimal conditions previously described (1.1 eq. of $\mathrm{H}_{2} \mathrm{O}_{2}$ at $80{ }^{\circ} \mathrm{C}$ ). 
However, in the presence of $2 \mathrm{wt} \%$ of $\mathrm{Cs}_{2.3} \mathrm{H}_{0.7} \mathrm{PW}_{12} \mathrm{O}_{40}$ catalyst, only $40 \%$ of $\mathrm{MO}$ was converted with $39 \%$ of MDHS after $2 \mathrm{~h}$ of reaction. In order to improve the reaction rate in order to be competitive with the homogeneous form, the catalyst amount was optimized to achieve a high yield of MDHS after $2 \mathrm{~h}$ of reaction. An increase of the catalyst loading from 2 to $6 \mathrm{wt} \%$ led to an increase of the MDHS yield from 39 to $79 \%$ (MO conversion of $80 \%$ ) after $2 \mathrm{~h}$ of reaction. The catalyst recycling was then studied using these reaction conditions. To this aim, after each cycle, the reaction media was centrifuged, and the recovered catalyst was then washed several time with ethyl acetate and water, dried at $60^{\circ} \mathrm{C}$ during $6 \mathrm{~h}$ and reused for the next cycle.

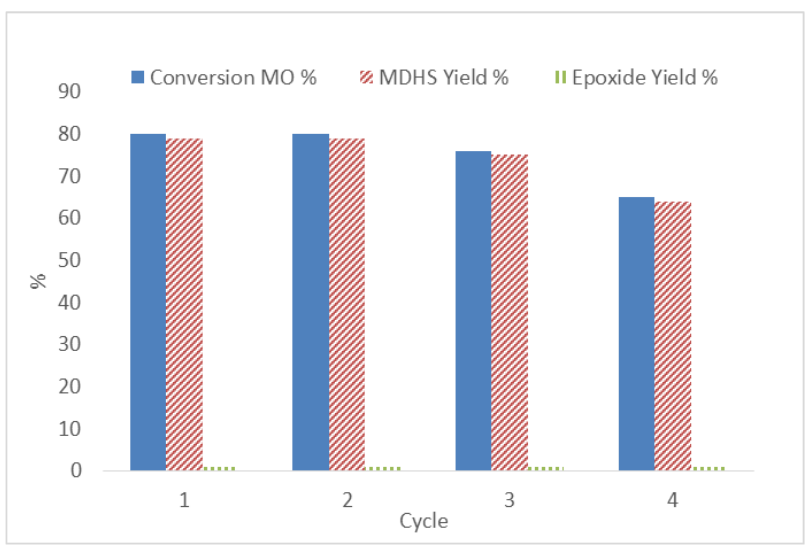

Figure 5. Recyclability of $\mathrm{Cs}_{2.3} \mathrm{H}_{0.7} \mathrm{PW}_{12} \mathrm{O}_{40}$ using $5 \mathrm{mmol}$ of $\mathrm{MO}, 1.1$ eq. of hydrogen peroxide and $6 \mathrm{wt} \%$ of catalyst at $80^{\circ} \mathrm{C}$ for $2 \mathrm{~h}$

The catalyst was recyclable up to 3 cycles without significant loss in MO conversion (76-80\%) and yield (75-79\%) in MDHS (Figure 5). After the third cycle, the conversion of $\mathrm{MO}$ and the yield of MDHS decreased.

In order to understand this loss of activity, $\mathrm{Cs}_{2.3} \mathrm{H}_{0.7} \mathrm{PW}_{12} \mathrm{O}_{40}$ was characterized before reaction and after the first and $4^{\text {th }}$ cycle. Elemental analysis of $\mathrm{W}$ and $\mathrm{P}$ was then performed on the $\mathrm{Cs}_{2.3} \mathrm{H}_{0.7} \mathrm{PW}_{12} \mathrm{O}_{40}$ catalyst before and after recycling (Table 1 ). Elemental analysis showed no significant difference in phosphorus content before and after reaction while a clear difference was observed with tungsten measurements. Before recycling, $\mathrm{Cs}_{2.3} \mathrm{H}_{0.7} \mathrm{PW}_{12} \mathrm{O}_{40}$ contained $63 \mathrm{wt} \%$ of $\mathrm{W}$ and after the fourth cycle, the weight percentage of $W$ decreased from 63 to $56 \%$. Thus activity loss was assigned to $W$ leaching, which became too significant past the fourth cycle.

Table 1. Weight percentage of $W$ and $P$ measured by ICP in $\mathrm{Cs}_{2.3} \mathrm{H}_{0.7} \mathrm{PW}_{12} \mathrm{O}_{40}$ before and after recycling.

\begin{tabular}{lcc}
\hline Catalyst & $\mathrm{W}(w t \%)$ & $\mathrm{P}(w t \%)$ \\
\hline Fresh $\mathrm{Cs}_{2.3} \mathrm{H}_{0.7} \mathrm{PW}_{12} \mathrm{O}_{40}$ & 63 & 0.9 \\
\hline $\mathrm{Cs}_{2.3} \mathrm{H}_{0.7} \mathrm{PW}_{12} \mathrm{O}_{40}$ after the $1^{\text {st }}$ run & 63 & 0.9 \\
\hline $\mathrm{Cs}_{2.3} \mathrm{H}_{0.7} \mathrm{PW}_{12} \mathrm{O}_{40}$ after the $4^{\text {th }}$ run & 56 & 0.8 \\
\hline
\end{tabular}

XPS analysis were also conducted to analyze the surface of the catalyst and the results were compared to the result obtained from the characterizations of commercial $\mathrm{H}_{3} \mathrm{PW}_{12} \mathrm{O}_{40}$ before (Figure 6) and after reaction (Figure 7).
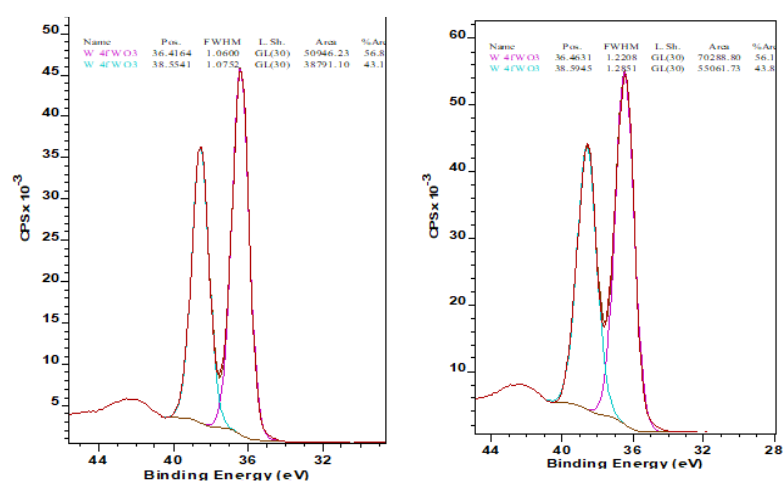

Figure 6. XPS spectrum of W4f of commercial catalyst (left) and $\mathrm{Cs}_{2.3} \mathrm{H}_{0.7} \mathrm{PW}_{12} \mathrm{O}_{40}$ before recycling (right).

XPS spectra of W4f of $\mathrm{H}_{3} \mathrm{PW}_{12} \mathrm{O}_{40}$ and $\mathrm{Cs}_{2.3} \mathrm{H}_{0.7} \mathrm{PW}_{12} \mathrm{O}_{40}$ before recycling (Figure 6) showed 2 peaks at $36.4 \mathrm{eV}$ and $38.5 \mathrm{eV}$ corresponding to tungsten oxide $\mathrm{WO}_{3}$ species of the $\mathrm{PO}_{4}\left(\mathrm{WO}_{3}\right)_{12}{ }^{3-} . \mathrm{Cs}_{2.3} \mathrm{H}_{0.7} \mathrm{PW}_{12} \mathrm{O}_{40}$ recovered after the first and the $4^{\text {th }}$ cycle, contained two forms of tungsten oxide: $\mathrm{WO}_{3}$ and $\mathrm{WO}_{2}$ (at $35.1 \mathrm{eV}$ ) meaning that the catalyst was modified after reaction. The presence of $\mathrm{WO}_{2}$ may have an impact on the recyclability process of the heterogeneous catalyst limiting the number of active species on the catalyst. However, the catalyst can be recyclable up to three cycles without using organic solvent or phase transfer agent.
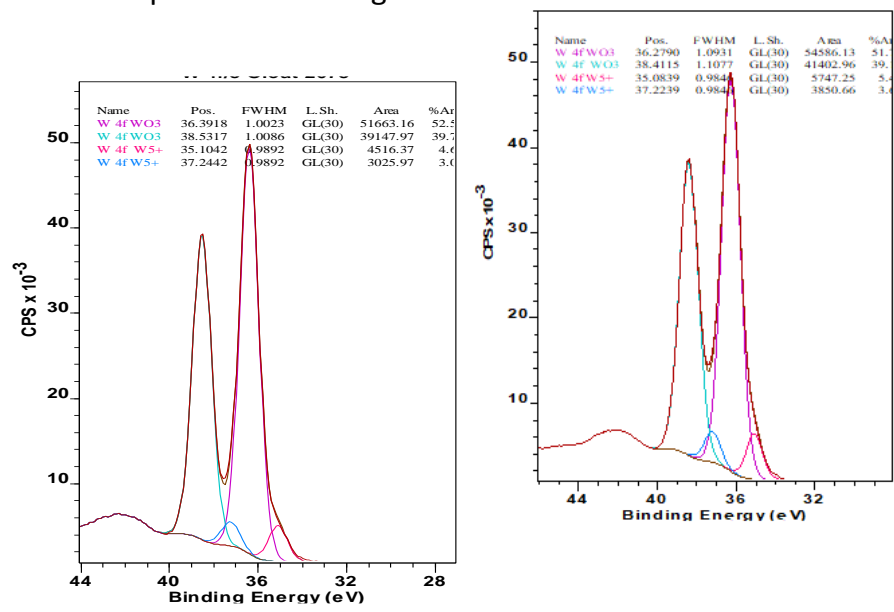

Figure 7. XPS spectrum of W4f of $\mathrm{Cs}_{2.3} \mathrm{H}_{0.7} \mathrm{PW}_{12} \mathrm{O}_{40}$ after the first cycle (left) and the $4^{\text {th }}$ cycle (right).

\section{Conclusions}

Herein, we have demonstrated that $\mathrm{H}_{3} \mathrm{PW}_{12} \mathrm{O}_{40}$ can be used to selectively convert methyl oleate into methyl-9,10dihydroxystearate (MDHS) with $99 \%$ yield. The yield to MDHS is higher than what was reported in the literature up to now (87\%). The mechanism involved in this reaction was the direct dihydroxylation of MO. The active species were peroxo- 
phosphotungstate anions formed in the presence of a certain amount of $\mathrm{H}_{2} \mathrm{O}_{2}$ that can be converted to phosphotungstate anions after the dihydroxylation of $\mathrm{MO}$. It was shown that no organic solvent, no phase transfer agent was required during this reaction, but an appropriate molar $\mathrm{H}_{2} \mathrm{O}_{2}$ /catalyst ratio (around 550 in the optimized conditions) is needed to reach the highest yield to MDHS from $\mathrm{MO}$. Hence, $\mathrm{H}_{2} \mathrm{O}_{2}$ concentration was $30 \%$, and under this concentration phase transfer agent are often required. In the absence of phase transfer agent, high concentration of $\mathrm{H}_{2} \mathrm{O}_{2}$ are used which can lead to safety issue. In this study, by controlling the molar $\mathrm{H}_{2} \mathrm{O}_{2}$ /catalyst ratio, diols from $\mathrm{MO}$ were obtained with low concentrated solution of $\mathrm{H}_{2} \mathrm{O}_{2}$ and no additional organic solvent. Moreover, a recyclable form was synthesized $\left(\mathrm{Cs}_{2.3} \mathrm{H}_{0.7} \mathrm{PW}_{12} \mathrm{O}_{40}\right)$ and was successfully recycled up to three cycles without significant loss in the catalytic performances.

\section{Conflicts of interest}

There are no conflicts to declare.

\section{Acknowledgements}

The authors would like to thank the French Ministry of National Education, Higher Education and Research as well as the FranceCanada Research Fund for the funding of the PhD grant of NA. The authors are also grateful to the Région Nouvelle Aquitaine for the funding of this project through the FR CNRS INCREASE 3707 (International Consortium on Eco-conception and Renewable Resources), the chair TECHNOGREEN and FEDER.

\section{Notes and references}

1 L.C. Meher, D.V. Sagar, S. N. Naik,. Renew. Sust. Energ. Rev., 2006, 10, 248.

2 Z. Helwani, M. R. Othman, N. Aziz, W. J. N. Fernando, J. Kim, Fuel Process. Technol., 2009, 90, 1502.

3 R. Jothiramalingam, M. K. Wang, Ind. Eng. Chem. Res., 2009, 48, 6162 .

4 D. Y. C. Leung, X. Wu, M. K. H. Leung, Appl. Energy, 2010, 87, 1083.

5 A. P. S. Chouhan, A. K. Sarma, Renew. Sust. Energ. Rev., 2011, 15, 4378.

6 M. E.Borges, L. Díaz, L., Renew. Sust. Energ. Rev., 2012, 16, 2839.

7 V. B. Borugadda, V. V. Goud, Renew. Sust. Energ. Rev., 2012, 16, 4763.

8 G. Santori, G. Di Nicola, M. Moglie, F. Polonara, F., Appl. Energy, 2012, 92, 109.

9 P. J. Deuss, K. Barta, J. G. de Vries, J. G., Catal. Sci. Technol., 2014, 4, 1174-1196.

10 A. Behr, A. Westfechtel, J. P. Gomes, Chem. Eng. Technol., 2008, 31, 700.

11 V. Aggarwal, Org. Process Res. Dev., 2000, 4, 233-234.

12 B.-J.Kollbe Ahn, S. Kraft, S. Sun, J. Mater. Chem., 2011, 21, 9498.

13 P. Metivier, M. Huet, L. Bernard, D. Charlemagne, WO Patent 2000044704, 2000.

14 F. E. Okieimen, C. Pavithran, I. O. Bakare, Eur J Lipid Sci Technol., 2005, 107, 330.

15 K. Tsubone, Japanese Patent 2005213241, 2005.
16 K. Tsubone, Japanese Patent 2005272429, 2005.

17 K. Tsubone, Japanese Patent 2005263765, 2005

18 K. Weissermel, H.-J. Arpe, Industrielle Organische Chemie. Wiley-VCH,Weinheim (Germany), 1998.

19 B. Cornils, W. A. Herrmann, R. Schlögl, C.-H. Wong, C.-H. (Eds.): Catalysis from A to Z - A Concise Encyclopedia. WileyVCH, Weinheim (Germany), 2000.

20 K. Yonehara, Y. Sumita, Japanese Patent 2005336064, 2005.

21 Y.-K. Lim, M. J. Lee, C.-S.Jung, J.-R. Kim, E. S.Yim, US Patent US20130053590, 2013.

22 R. Hage, A. Lienke, Angew. Chem. Int. Ed., 2005, 45, 206.

23 E. J. Geiger, N. M. Becker, L. A. Armbruster, WO Patent 2006094227, 2006.

24 Y. Usui, K. Sato, M. Tanaka, Angew. Chem. Int. Ed., 2003, 42, 5623.

25 G. J. Piazza, A. Nunez, T. A. Foglia, J. Am. Oil Chem. Soc., 2003, 80, 901.

26 M. M. Cecchini, F. De Angelis, C. lacobucci, S. Reale, M. Crucianelli, Appl. Catal. A: Gen., 2016, 517, 120.

27 S. P. Teong, X. Li, Y. Zhang, Green Chemistry, 2019, 21, 5753; M. Melchiorre, V. Benessere, M. E. Cucciolito, C. Melchiorre, F. Ruffo , R. Esposito, ChemistrySelect, 2020, 5, 1396. V. Benessere, M. E. Cucciolito, A. De Santis, M. Di Serio, R. Esposito, F. Ruffo, R. Turco, J. Am. Oil Chem. Soc., 2015, 92, 1701.

28 T. M. Luong, H.; Schriftman, D. Swern, D., J. Am. Oil Chem. Soc., 1967, 44, 316.

29 E. Santacesaria, M. Ambrosio, A. Sorrentino, R. Tesser, M. Di Serio, Catal. Today, 2003, 79-80, 59.

30 A. Soutelo-Maria, J.-L.Dubois, J.-L. Couturier, G. Cravotto, Catalysts, 2018, 8, 464

31 C. Venturello, R. Daloisio, J. C. J. Bart, M. A. Ricci, J. Mol. Catal. 1985, 32, 107-110

32 C. Venturello, R. Daloisio, J. Org. Chem., 1988, 53, 1553.

33 L. Carlos de la Garza, K. De Oliveira Vigier, G. Chatel, A. Moores, Green Chem., 2017, 19, 2855.

34 F. Zhang, M. Chen, X. Jia, W. Xu, N. Shi, Process Saf. Environ. Protection, 2019, 126, 1.

35 R. Noyori, M. Aoki, K. Sato, K., Chem.Comm., 2003, 16, 1977.

36 T. Strassner, Adv. Phys. Org. Chem., 2003, 38, 131.

37 A. Köckritz, A. Martin, Eur. J. Lipid Sci. Technol., 2008, 110, 812.

38 A. Gharib, M. Jahangir, M. Roshani, N. Noroozi Pesyan, J. Scheeren, Synth. React. Inorg. M., 2015, 45, 350. 